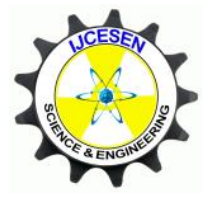

Copyright (C) IJCESEN
International Journal of Computational and

Experimental $\boldsymbol{S}$ cience and Engineering

(IJCESEN)

Vol. 3-No.1 (2017) pp. 33-37

http://iakkurt.dergipark.gov.tr/ijcesen

Research Article

\title{
Investigation of notch effect on vibration behavior of filled and unfilled composite beam \#
}

\author{
Ersin DEMIR*, Metin SAYER \\ Pamukkale University, Mechatronics Engineering Department, 20070, Denizli, Turkey \\ * Corresponding Author : edemir@pau.edu.tr \\ (First received 25 November 2016 and in final form 20 February 2017) \\ \# Presented in " $3^{\text {rd }}$ International Conference on Computational and Experimental Science and Engineering (ICCESEN-2016)"
}

Keywords
Vibration
Notch
Filled Composite

Keywords

Notch

Composite

\begin{abstract}
In this study, the effect of the notches on natural frequencies of ceramic particles filled and unfilled unidirectional composite beams are investigated numerically. Shape, number, size and location of the notch are examined for unfilled unidirectional composite beam. Moreover, the effect of the particle additives on the natural frequency of the composite beam with $\mathrm{V}$ notch is also examined. Three types of notch shape are considered: $\mathrm{U}, \mathrm{V}$ and square $(\mathrm{S})$. SiC, Al2O3 and $\mathrm{B} 4 \mathrm{C}$ are used as the additive particles. According to the results, minimum natural frequency is found in the $\mathrm{S}$ notch. Furthermore, it can be seen from the results that natural frequency of $S$ notch is the most affected by increase in the number, size and location of notch. As for the effect of the particle additives, maximum natural frequency is found in the beam with filled B4C and V notch as compared with the others.
\end{abstract}

\section{Introduction}

The subject of free vibration behaviours of composite beams has attracted the attention of many researchers. A lot of studies have been done on this subject. But it can be seen from the literature survey that there are not enough studies on vibration behaviours of composite beams with notch. Some of these papers are: Capozucca [1] investigated the experimentally dynamic behavior of composite elements with damage due to double notches considering the Carbon Fiber Reinforced Polymer (CFRP) cantilever beam specimens. He reported that the basis of the results obtained for undamaged and damaged CFRP cantilever beam, the non-destructive free vibration analysis method was available for assessing CFRP beams in the damage condition. Jiangyi et al. [2] derived the universal expression of the modal parameters for a damaged beam under arbitrary boundary conditions. They performed the delta function is first employed to describe a notch damage in the beam and consequently to derive the governing equation for the damaged beam. Capozucca and Bonci [3] analyzed the damaged and undamaged CFRP laminate elements under free vibration experimentally and theoretically. Damaged CFRP laminate specimens were subjected to local, increasing, reduction of bending stiffness due to double notches at different sections with different widths. Frequency Response Functions depicted in the frequency domain were recorded under free vibration to extract natural frequencies and the changes due to different damage degrees were analyzed. Pham and Sun [4] studied on progressive failure analysis of notched cross-ply CFRP composite. The carbon/epoxy composite laminated with [90/0]s layup was tested using double-notched specimens loaded in tension. As a result, they were obtained reasonably good agreement between experimental results and simulation results.

Capozucca and Magagnini [5] investigated the detection of damages as a consequence of unbonding and/or notches were by dynamic response of RC beams with NSM Carbon-FRP circular rods. The behavior of beams was analyzed through experimental free vibrations on four RC beam models. Akhtyamov and Il'gamov [6] studied on the location and sizes of a notch in a beam which were determined from the beam deflection at several points and also from its flexural eigenfrequencies. Finally, they found that the use of the first eigenfrequencies of flexural vibrations of 
the beam with respect to different axis provides a more accurate identification than the use of eigenfrequencies of flexural vibrations relative to one axis. Yoon et al. [7] presented a global fitting method (GFM) incorporating generic mode shape forms. This method requires the mathematical forms corresponding to displacement mode shapes for a one-dimensional beam instead of using the baseline data obtained before the beam damaged. Convergence tests were performed for the FEA data with and without a notch in two beams to select an optimum mesh size. Finally, damage detection method was applied to the experimental data obtained from two notched beams to detect a location and size of the notch.

The present study deals with the effects of the shape, number, size and location of the notch on natural frequency of ceramic particles filled and unfilled unidirectional composite beams. The effect of the adding particle additives to the composite beam with $\mathrm{V}$ notch on the natural frequency is also investigated. The natural frequency analysis is performed numerically by using Finite Element based commercial program SolidWorks ${ }^{\circledR}$ (SolidWorks Corp., USA).

\section{Materials and Models}

\subsection{Beam Models}

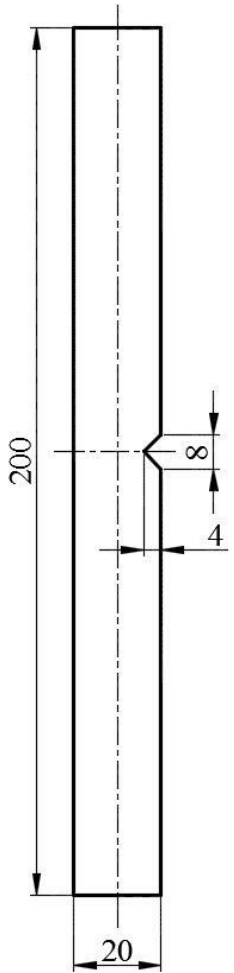

(a) V notched Beam

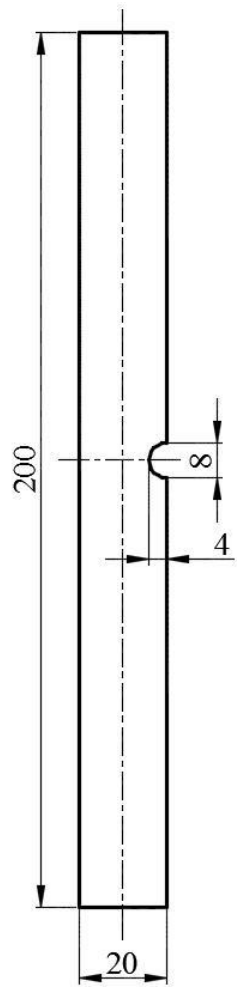

(b) U notched Beam

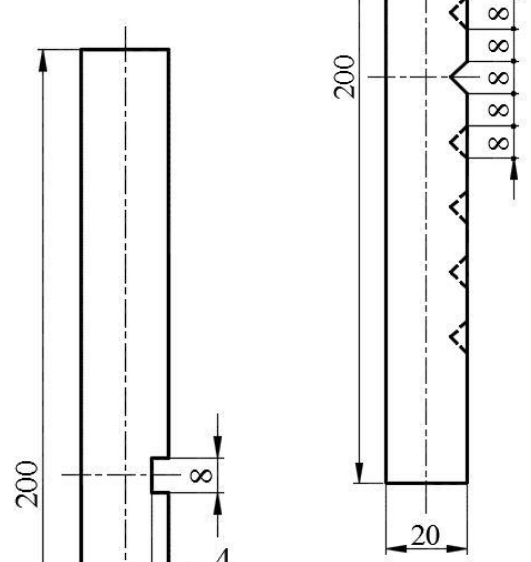

(a) Increase in the Number of Notch
In order to see the effect of notch number, it is increased from 1 to 9 with an odd number increment. This increase is performed symmetrically with respect to horizontal axis. The increase in the number of $\mathrm{V}$ notches is represented in Figure 2(a). Furthermore, all notch types are also investigated in the study.

The effect of the notch size is investigated by increasing the height of the notch from $8 \mathrm{~mm}$ to 20 $\mathrm{mm}$ by the increment of $2 \mathrm{~mm}$. The notch size is increased based on the middle right side of the beam. Increase in the notch size for the $\mathrm{V}$ notch is shown in Figure 2(b).

To see the effect of notch location, the location of the notch is changed. The location of the notch is measured from the one end of the beam as shown in Figure 2(c). This distance is increased from $25 \mathrm{~mm}$ to $175 \mathrm{~mm}$ by the increment of $25 \mathrm{~mm}$.

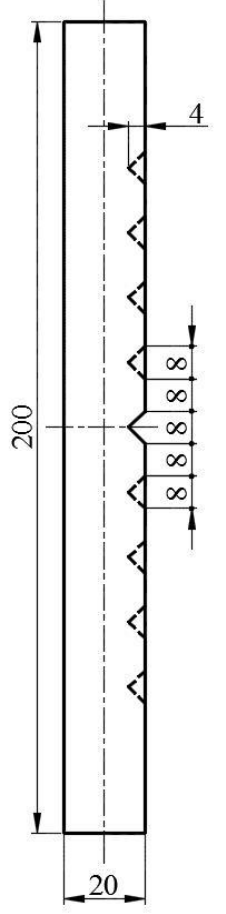

Figure 2. Change in the Number, Size and Location of Notch

\subsection{Beam Materials}

In this study, the beam is made of unidirectional Eglass/epoxy composite material with eight layers. Its mechanical properties are taken from Sayer [8]. Four types material are handled in the study. Three of them are filled with various ceramic particles 
and one of them is neat composite. The particular filler materials are Silicon Carbide (SiC), Aluminium Oxide (A12O3) and Boron Carbide (B4C). The mechanical properties of the beam materials are given below [8].

Table 1. The mechanical properties of the beams [8].

\begin{tabular}{|c|c|c|c|c|}
\hline \multirow{2}{*}{$\begin{array}{c}\text { Mechanical } \\
\text { Properties }\end{array}$} & \multicolumn{4}{|c|}{ Quantity of Filler (wt\%) } \\
\cline { 2 - 5 } & $\mathbf{0 \%}$ & $\begin{array}{c}\mathbf{1 0 \%} \\
\text { SiC }\end{array}$ & $\begin{array}{c}\mathbf{1 0 \%} \\
\mathbf{A l 2 0 3}\end{array}$ & $\begin{array}{c}\mathbf{1 0 \%} \\
\mathbf{B 4 C}\end{array}$ \\
\hline $\mathbf{E}_{\mathbf{1}}$ (MPa) & 30100 & 35700 & 37650 & 41985 \\
\hline $\begin{array}{c}\mathbf{E}_{\mathbf{2}}=\mathbf{E}_{\mathbf{3}} \\
(\mathbf{M P a})\end{array}$ & 7405 & 9795 & 9936 & 10043 \\
\hline $\begin{array}{c}\mathbf{G}_{\mathbf{1 2}}=\mathbf{G}_{13} \\
(\mathbf{M P a})\end{array}$ & 2879 & 2255 & 2551 & 2715 \\
\hline $\mathbf{v}_{\mathbf{1 2}}$ & 0.32 & 0.32 & 0.32 & 0.32 \\
\hline
\end{tabular}

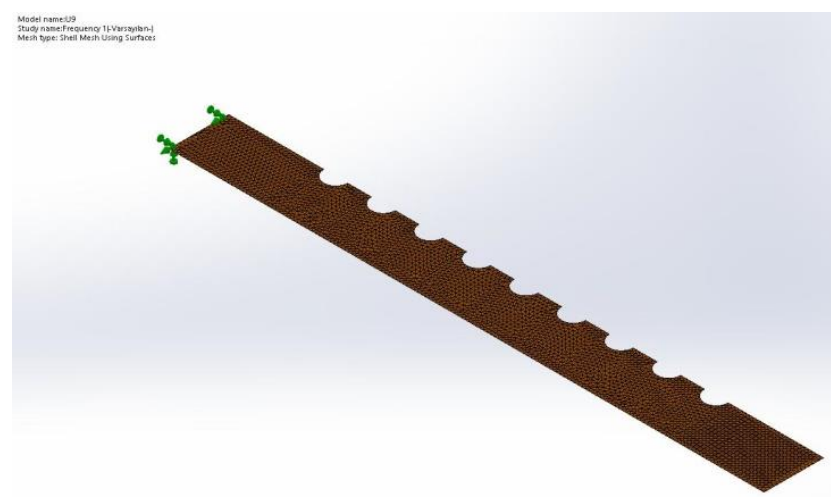

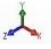

(a) Beam Model with Free Meshed

\begin{tabular}{|l|l|l|l|l|}
\hline $\mathbf{v}_{21}=\mathbf{v}_{31}$ & 0.079 & 0.087 & 0.084 & 0.076 \\
\hline
\end{tabular}

beams are investigated in the present study. The effects of these are examined in the following subsections step by step.

\subsection{Effect of notch shape}

In the analysis, three types notch shape are considered: V, U and S. These notches are located on the middle of the beam and the dimensions of the notches are shown in Figure 1. So, the effect of notch shapes on the natural frequency of the unfilled composite beam is depicted in Figure 4. The natural frequency value obtained for unnotched beam is also added in the figure. As expected, the notches decrease the natural frequency.

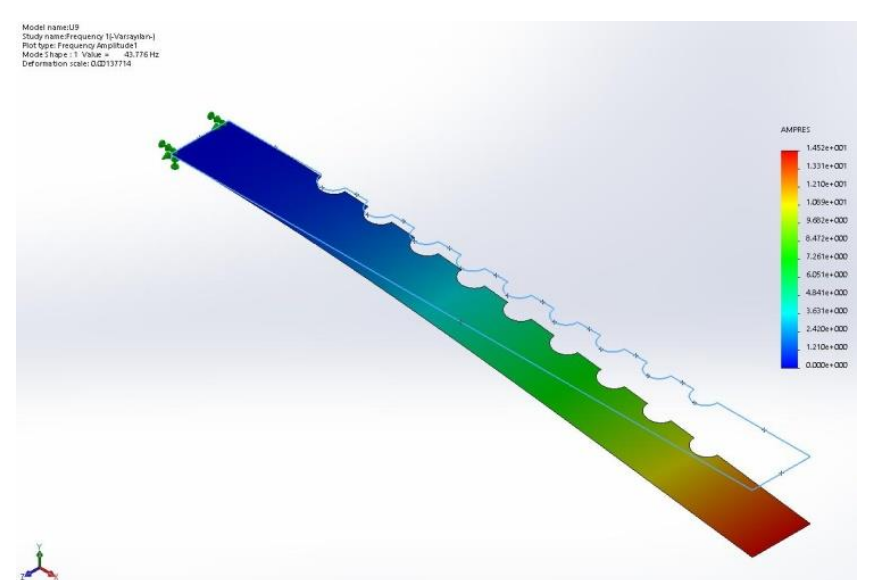

(b) Beam Model After Analysis

Figure 3. A Beam Model in SolidWorks

\section{Numerical Analysis}

The vibration analysis of the beams is performed by using Finite Element based commercial program SolidWorks ${ }^{\circledR}$ (SolidWorks Corp., USA). The beam models are drawn as wire-frame in Sketch section as described in Section 2.1 and then beam surfaces is obtained in Surface section of the program. Each materials listed in Table 1 is defined as Custom Material, and the material properties are entered into the program for each material. The finite element analysis is performed in the Simulation module of the program. The material defined previously is assigned to the model and the beam is defined as composite shell element in the Simulation module. The thickness and the orientation angle of each layer are also entered in this section. Then, the clamped-free boundary condition is applied to the model. The program is run after the fine meshing process. The free meshed model with triangular elements and a view of the model after analysis are shown in Figure 3.

\section{Results and Discussion}

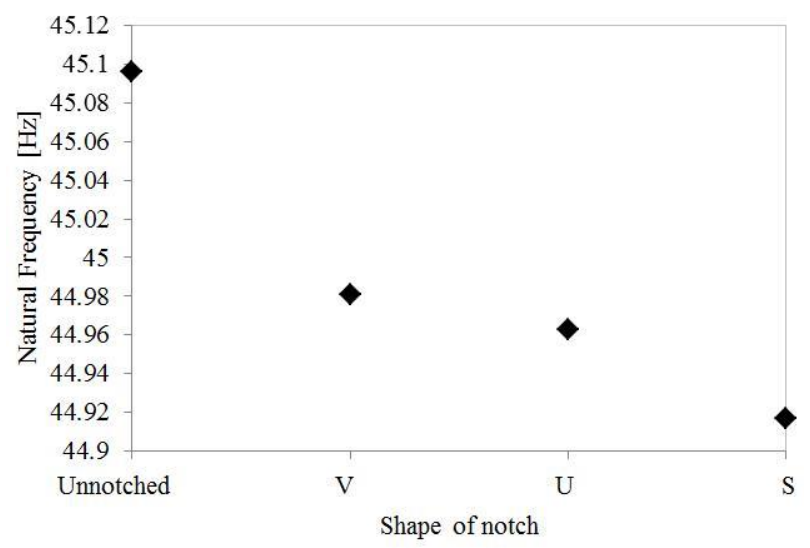

Figure 4. The variation in the natural frequencies of the beams with different notch shapes 


\subsection{Effect of notch number}

As previously mentioned, the number of notch is increased with respect to the middle axis of the beam to see the effect of notch number. Figure 5 shows the variation in the natural frequencies of the beams with different notch numbers. According to the figure, the increase in the number of notches reduces the natural frequency. But, this reduction is more than the others for the beam with $\mathrm{S}$ notch.

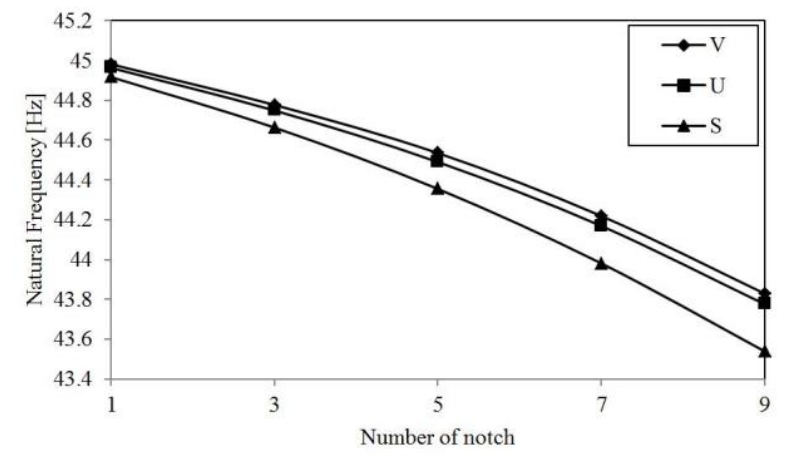

Figure 5. The variation in the natural frequencies of the beams with different notch numbers

It can be seen from the figure that the difference in the natural frequencies of the beams with one notch is less than those with nine notches. Besides, the curves obtained for $\mathrm{V}$ and $\mathrm{U}$ notches are quite close to the each other. As a result of the increase in the number of notches, the natural frequency decreases.

\subsection{Effect of notch size}

It can be seen in Figure 6 that the natural frequencies decrease with increasing the notch size. This figure is very similar to Figure 5. But, the curves are separated from each other more quickly. This means, the effect of the notch size on the natural frequency is greater than the effect of notch number.

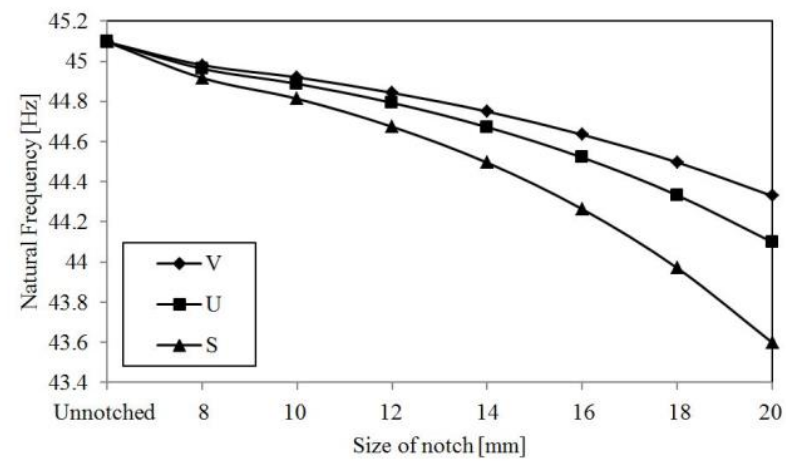

Figure 6. The variation in the natural frequencies of the beams with different notch sizes

\subsection{Effect of notch location}

Figure 7 shows the variation of natural frequency with the change in the location of the notch. It can be seen from the figure that interesting results are obtained from varying the location of the notch.

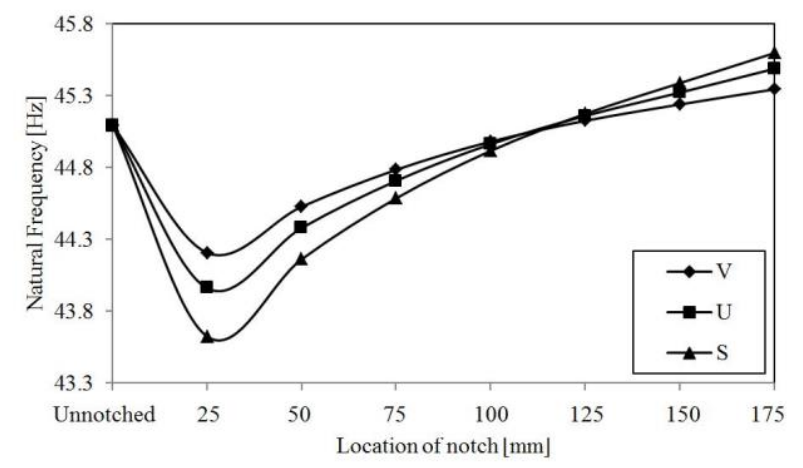

Figure 7. The variation in the natural frequencies of the beams with different notch locations

So, the natural frequency increases with increasing the distance between the notch location and the clamped end of the beam. It is also seen the figure that the natural frequencies obtained for the values greater than approximately $115 \mathrm{~mm}$ are greater than those for unnotched beam. In addition, the natural frequency value of the beam with $\mathrm{V}$ notch is larger than the others until about $115 \mathrm{~mm}$. But this effect reverses after $115 \mathrm{~mm}$.

\subsection{Effect of filler}

In order to see the effect of filler, it is only use V notch that is the most commonly encountered notch shape. The effect of the filler is shown in Figure 8. It can be seen from the figure that the natural frequencies of the filled composite beams with $\mathrm{V}$ notch are greater than that of unfilled composite beam.

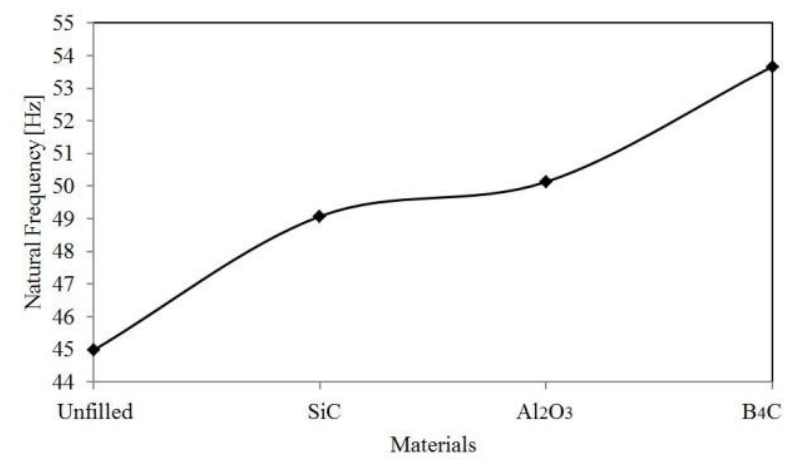

Figure 8. The variation in the natural frequencies of the beams with different fillers

The maximum natural frequency is obtained for the composite beam filled by B4C. The natural frequencies of the composite beam filled by $\mathrm{SiC}$ and $\mathrm{Al} 2 \mathrm{O} 3$ are almost the same. 


\section{Conclusion}

The following conclusions can be drawn from the study.

- $\mathrm{S}$ notch decreases the natural frequency more than the $\mathrm{U}$ and $\mathrm{V}$ notches.

- The natural frequency decreases with increasing the number of notches. But, this decrease is more in the beam with $\mathrm{S}$ notch.

- The natural frequency decreases with the increase in the notch size. But, this decrease is less for the beams with $\mathrm{U}$ and $\mathrm{V}$ notches.

- The natural frequency increases with increasing the distance between the clamped end of the beam and the notch location. Interestingly, the natural frequencies of notched beams exceed the natural frequency of unnotched beam after about $115 \mathrm{~mm}$.

- Fillers in the composite beam increases the natural frequency. The natural frequency of the composite beam filled by B4C is larger than those of $\mathrm{SiC}$ and $\mathrm{Al} 2 \mathrm{O} 3$. The natural frequencies of the composite beam filled with $\mathrm{SiC}$ and $\mathrm{Al} 2 \mathrm{O} 3$ are almost the same.

\section{Acknowledgments}

The authors would like to thank Pamukkale University Scientific Research Council due to the supports.

\section{References}

[1] Capozucca R. "Vibration of CFRP cantilever beam with damage" Composite Structures 116 (2014) 211222. DOI: 10.1016/j.compstruct.2014.04.027

[2] Chen J. Y., Fan L. G. and Qin D. C. "Free Vibration of Damaged Beam Structure with a Notch Defect" International Conference on Vibration, Structural Engineering and Measurement (ICVSEM2012) 19-21, October, (2012) Shanghai-China. DOI: 10.4028/www.scientific.net/AMM.226-228.44

[3] Capozucca R. and Bonci B. "Notched CFRP laminates under vibration" Composite Structures 122 (2015) 367-375. DOI:10.1016/j.compstruct.2014.11.062

[4] Pham D. C. and Sun X. "Experimental and Computational Studies On Progressive Failure Analysis Of Notched Cross-Ply CFRP Composite" International Journal of Computational Materials Science and Engineering, 01(03) (2012) DOI: $10.1142 / \mathrm{S} 2047684112500236$

[5] Capozucca R. and Magagnini E. "Vibration of RC beams with NSM CFRP with unbonded/notched circular rod damage" Composite Structures 144 (2016) 108-130. DOI:1016/j.compstruct.2016.02.027
[6] Akhtyamov A. M. and Il'gamov M. A. "Flexural model for a notched beam: direct and inverse problems" Journal of Applied Mechanics and Technical Physics, 54(1) (2013) 132-141. DOI: $10.1134 / \mathrm{S} 0021894413010161$

[7] Yoon M.-K., Heider D., Gillespie Jr J.W., Ratcliffe C. P., Crane R. M. "Local Damage Detection with the Global Fitting Method Using Mode Shape Data in Notched Beams" Journal of Nondestructive Evaluation (2009) 28: 63-74. DOI 10.1007/s10921-009-0048-6

[8] Sayer M. "Elastic properties and buckling load evaluation of ceramic particles filled glass/epoxy composites" Composites: Part B 59 (2014) 12-20. DOI: 10.1016/j.compositesb.2013.11.016 